\title{
RESENHA
}

\section{FEMINIST THEORY AND THE CLASSICS}

Pedro Paulo A. Funari**

Na série Thinking Gender, o volume dedicado à "Teoria Feminista e os Estudos Clássicos" compõe-se de onze capítulos escritos por pesquisadores das áreas de Letras e Arqueologia Clássicas. Os ensaios dividem-se entre quatro campos temáticos: Redefinindo o campo; o homem inscreve a mulher; a abordagem ginocêntrica; epistemologia e cultura material. Já na Introdução, Nancy Sorkin Rabinowitz alerta que os Estudos da Antigüidade Clássica, com raras exceções, têm sido anti-teóricos em geral e anti-feministas em particular (p.1). Conservadores, em termos políticos e científicos, os classicistas tendem a não se colocar questões relativas, por exemplo, às classes sociais, ao gênero, à etnicidade, à relação entre o autor e seu público e às influências contemporâneas sobre o analista (p.5). No entanto, os Estudos Clássicos não precisam limitar-se a estes horizontes tradicionais e, ao contrário, possuem uma característica que propicia sua inserção nas teorizações contemporâneas: a interdisciplinaridade. Língua, Literatura, Antropologia, Arqueologia, História da Arte, entre outras Ciências Humanas, constituem o núcleo interdisciplinar de atuação do classicista que, pela diversidade de paradigmas em confronto, pode analisar criticamente as sociedades antigas (p.6).

\footnotetext{
*Ed. por Nancy Sorkin Rabinowitz e Emy Richlin. Nova Iorque, Routledge, 1993, 314 páginas.

** Professor Doutor em História Antiga do Departamento de História - Unicamp.
}

Cadernos Pagu (3) 1994: pp. 267-272. 
Feministy theory

Os diversos artigos mesclam, propositadamente, teorias feministas e análises da documentação antiga. No que se refere aos modelos contemporâneos, caberia destacar a variedade de abordagens e seu efeito no estudo do material clássico. Assim, o Feminismo negro (pp. 23-43), a Teoria do Filme (pp. 102-121), a Ginocrítica (pp. 125-144), a Antropologia dos Ameríndios (pp. 145-180), a Perspectiva Lésbica (pp.181-208), o Marxismo (pp.211-237), entre outras abordagens, demonstram a variedade de teorias postas em jogo pelos autores. Os temas tratados abrangem generalizações, sobre os cânones literários (pp.44-74) ou sobre a Arqueologia feminista (238-271), que se alternam com estudos específicos sobre Safo (pp. 125-144), Sêneca (pp. 102-124) ou sobre a Poesia Romana (pp. 75-101).

A feminista negra Judith P. Haley constata que sua introdução ao Latim e à cultura clássica deveu-se à sua mãe e tias cuja leitura da Antigüidade contrastava seja com o racismo seja com o machismo predominantes. Não era à toa que escravos e quilombolas aprendiam latim e grego, pois a cultura clássica podia servir de elemento de contestação, e não somente de confirmação, do status quo. Hallett chama a atenção para o fato de que Propércio, escrevendo no início do Principado, apresenta as mulheres como "dinâmicas, independentes, com voz ativa" e interpreta sua representação como "feminista, no contexto cultura da época de Augusto, diversa do feminismo de fins do século XX, mas feminista" (p.63). Além de Hallett, também Gold aceita que se interpretem alguns autores romanos, em particular, como feministas, mas outras autoras como as organizadoras do volume, Nancy S. Rabinowitz e Amy Richlin chegam à conclusão diametralmente oposta: "eram extremamente machistas, violentos contra as mulheres, dominados pelas fantasias do estupro" (p.290). Estas leituras, completamente antagônicas, demonstram a ambigüidade essencial desses testemunhos masculinos. 
A mulher representada pelos homens pode ser interpretada de múltiplas maneiras. A própria definição do feminino entra em questão e Gold opõe o Feminismo francês, preocupado com o discurso, ao Feminismo Anglo-Americano, mais empírico e ativista (pp. 78-83). Gold propõe uma leitura, nesses textos, "buscando o que está escondido, desenfatizado, deixado de lado, ou com sua articulação negada, tentado evidenciar os espaços produzidos, nesses textos, sobre os quais o autor não controla e nos quais a "mulher" pode ser encontrada" (p.86). Diana Robin, seguindo esta trilha, tenta desvendar a presença do útero no imaginário feminino de Sêneca. Bella Zweig lembra que Platão e Sócrates afirmavam serem suas idéias derivadas de mulheres, Aesara e Diotima (Pl.Symp.201d). O discurso totalitário da submissão feminina parece não se sustentar nem mesmo nas vozes masculinas.

As raríssimas evidências diretas das mulheres também se prestam a interpretações. Marilyn B. Skinner procura reconstruir o discurso de Safo não como uma poetisa menor, pálida imitadora de Alceu, Píndaro e outros autores de poemas para as virgens casadoiras (partheneia), mas como "parte de uma difundida tradição oral feminina, passada de mãe para filha, em composições que serviam, efetivamente, como um mecanismo de oposição ao Patriarcado" (p.135). É interessante observar que, para manter a visão tradicional de Safo não se furtaram, os estudiosos modernos, a "masculinizar" as terminações dos adjetivos para indicar que o objeto do desejo não era outra mulher, mas um homem!

Shelby Brown, em seu trabalho sobre a Pesquisa Feminista e a Arqueologia, inicia lembrando o caráter "masculino" do trabalho arqueológico, sujo, desconfortável, cansativo, pesado (p.241-2). Preconceito muito comum, também, na Arqueologia Brasileira, cujos praticantes não raras vezes referem-se, jocosamente, à incapacidade feminina em executar 
tarefas arqueológicas fundamentais como...trocar pneus! Brown explicita o papel reservado às arqueólogas: "muitos diretores de escavação sentem-se desconfortáveis com mulheres (embora muitos tenham suas alunas favoritas), com a inevitável consequiência de favorecer os homens. Participei de escavações nas quais as relações sexuais entre o diretor e seus amigos e aluninhas eram consideradas normalíssimas. O efeito "harém" derivado da constituição de um corpo numeroso de arqueólogas acaba por influenciar as mulheres a desejarem ter um relacionamento com um diretor...".

No entanto, a introdução do gênero na pesquisa arqueológica permite questionar, a nível hermenêutico, a própria pretensão de neutralidade científica da Arqueologia. A tipologia, por exemplo, "chata, tediosa, enfadonha e difícil", típica dos anos 70 e 80, pode ser criticada e entendida não com a descrição da realidade, mas como mecanismos "descritivos, categorizadores, classificadores inconscientes de artefatos a partir de noções masculinas ocidentais de importância, despersonalizando as narrativas ao enfocar os objetos em vez das pessoas" (p.253).

Em termos gerais, o volume apresenta uma oscilação entre duas tendências quanto às mulheres na Antigüidade Clássica. Algumas autoras consideram que o Patriarcado e a falocracia eram tão fortes que a tarefa maior consiste no estudo dos meios de opressão masculina. Outras, ao contrário, ressaltam a autonomia feminina, tornada acessível seja na sua própria produção seja no discurso masculino sobre as mulheres. Estas duas interpretações, contrapostas, das mesmas fontes antigas, não deixam lugar a dúvidas quanto à ambigüidade dos testemunhos. Outra oposição de igual importância refere-se às autoras que privilegiam a constituição da mulher através de um discurso não fálico, que não poderia ter surgido na Antigüidade Clássica, e aquelas que se propõem a atribuir significação decisiva à práxis da mulher, seguramente detectável no mundo 
antigo. Embora estas contraposições apareçam matizadas nos diferentes artigos, há, claramente, duas tendências nítidas e conflitantes: uma delas privilegia a vida quotidiana das mulheres e deriva do convívio feminino uma necessária especificidade, autonomia, diferença e, até, sensibilidade femininas. Deste ponto de vista, aceitar a existência de uma totalitária falocracia seria aceitar uma visão masculina, falocêntrica, do passado. Judith P. Hallett questiona, muito oportunamente, o modelo androcêntrico de Michel Foucault, a oposição entre a atividade masculina e a passividade feminina (e, por consequência, do efebo) e constata que sua aceitação depende, em grande parte, do desconhecimento dos autores antigos (p.48).

Isto conduz à questão da relevância do estudo dos clássicos para o movimento feminista. Diversas autoras ressaltam que este conhecimento justifica-se, justamente, pelo poder emancipador da compreensão, por oposição à aceitação dos modelos interpretativos. Apenas o trato com as evidências antigas permite compreender e criticar as formulações contemporâneas sobre a onipotência e profundidade do chamado totalitarismo falocrata do Patriarcado Ocidental. Uma tradição multi-milenar de opressão parece pesar, inibir e limitar as mulheres ainda hoje. Shelley P. Haley refere-se a uma prática acadêmica muito significativa: "o objetivo do professor consistia em levar as estudantes às lágrimas" (26). Esta estratégia de opressão baseia-se em toda uma série de estereótipos femininos interiorizados pelas alunas: passivas, submissas, devem receber o conhecimento do professor. Passiva significa sofrida, pati é o verbo sofrer, tanto lamentar-se quanto sujeitar-se à ação. Submeter-se é colocar-se em baixo. Estas lágrimas estariam sendo produzidas pela duradoura ditadura falocrática, constatada no discurso sobre uma Antigüidade masculina e reafirmada no presente pela ontológica oposição entre atividade, poder e falo e passividade, submisso e ausência de falo. 
Feministy theory

Rabinowitz e Richlin produziram um livro essencial ao desafiarem a aceitação desses modelos sobre a Antigüidade Clássica. Safo não precisa ser uma poetisa menor a serviço das virgens casadoiras. Os próprios homens, em suas laudes mulierum, não precisam ser desqualificados e pode buscar-se a sophia também nas mulheres reportadas por Platão. As amadas não precisam perder a autonomia afetiva que apresentam no discurso de seus amantes. O conhecimento das mulheres antigas permite, na verdade, uma melhor compreensão da relação entre os sexos na Antigüidade Clássica e, talvez o mais essencial, contribui para a crítica das utilizações ideológicas contemporâneas das evidências antigas. $\mathrm{O}$ mérito maior deste volume, para classicistas e feministas a um só tempo, consiste no questionamento das noções correntes, inconscientemente incorporadas. A beleza dos textos e as interpretações variadas apenas reforçam este objetivo primeiro do livro: de omnibus dubitandum, tudo questionar criticamente, preceito clássico que não deve ser atribuído aos falocratas mas que pode ser usado para criticá-los. 